\title{
Epigenetic status of LINE-1 predicts clinical outcome in early-stage rectal cancer
}

\author{
A Benard ${ }^{1,2}$, C J H van de Velde ${ }^{2}$, L Lessard ${ }^{1}$, H Putter $^{3}$, L Takeshima ${ }^{1}$, P J K Kuppen ${ }^{2}$ and D S B Hoon *,1 \\ ${ }^{1}$ Department of Molecular Oncology, John Wayne Cancer Institute, Santa Monica, CA 90404, USA; ${ }^{2}$ Department of Surgery, \\ Leiden University Medical Center, Leiden 2300RC, The Netherlands and ${ }^{3}$ Department of Medical Statistics and Bioinformatics, \\ Leiden University Medical Center, Leiden 2300RC, The Netherlands
}

Background: We evaluated the clinical prognostic value of methylation of two non-coding repeat sequences, long interspersed element 1 (LINE-1) and Alu, in rectal tumour tissues. In addition to DNA methylation, expression of histone modifications H3K27me3 and H3K9Ac was studied in this patient cohort.

Methods: LINE-1 and Alu methylation were assessed in DNA extracted from formalin-fixed paraffin-embedded tissues. A pilot (30 tumour and 25 normal tissues) and validation study (189 tumour and 53 normal tissues) were performed. Histone modifications H3K27me3 and H3K9Ac were immunohistochemically stained on tissue microarrays of the study cohort.

Results: In early-stage rectal cancer (stage I-II), hypomethylation of LINE-1 was an independent clinical prognostic factor, showing shorter patient survival ( $P=0.014 ; \mathrm{HR}: 4.6)$ and a higher chance of tumour recurrence $(P=0.001 ; \mathrm{HR}$ : 9.6). Alu methylation did not show any significant correlation with clinical parameters, suggesting an active role of LINE-1 in tumour development. Expression of H3K27me3 (silencing gene expression) and H3K9Ac (activating gene expression) in relation to methylation status of LINE-1 and Alu supported this specific role of LINE-1 methylation.

Conclusion: The epigenetic status of LINE-1, but not of Alu, is prognostic in rectal cancer, indicating an active role for LINE-1 in determining clinical outcome.

Under the current TNM (tumour node metastasis) staging system (American Joint Committee on Cancer, AJCC (Edge, 2010)) and treatment guidelines (National Cancer Institute, NCI), there is both over- and undertreatment of rectal cancer patients (Zeestraten et al, 2012). In our search for biomarkers that can complement the current TNM-staging system as well as aid in subsequent treatment decisions for rectal cancer patients, we assessed genome-wide DNA methylation using repeat sequences LINE-1 (long interspersed element) and Alu, and global histone modifications in rectal tumour tissues.

Changes in epigenetic mechanisms regulating gene expression, including DNA methylation of $\mathrm{CpG}$ dinucleotides, are major factors in tumorigenesis (Lao and Grady, 2011). We have previously reported that epigenomic aberrations have a significant role in tumour progression and clinical outcome in rectal cancer (de Maat et al, 2008). These studies showed that methylation of non-coding regions can be used as prognostic biomarkers in colorectal cancer. Human DNA contains large numbers of non-coding repeat sequences, the most studied sequences being LINE and Alu repeats. LINE-1 repeat sequences constitute about $17 \%$ of the total human genome, are present on most of the chromosomes, and comprise about 50 different subfamilies (Sellis et al, 2007). Alu repeats constitute about $11 \%$ of the human genome (Lander et al, 2001). Because of their abundance in the human genome, methylation of LINE-1 and Alu sequences has been used as surrogate for genome-wide DNA methylation status (Weisenberger et al, 2005). Hypomethylation of both LINE-1 and Alu sequences has been associated with malignancies (Burwinkel and Kilimann, 1998), including sporadic cases of haemophilia (Kazazian et al, 1988) and several other types of cancer (Miki et al, 1992; Chen et al, 2005; Cho et al, 2007; Sunami et al, 2008, 2011a; Bae et al, 2011; Beck et al, 2011). In addition to DNA methylation, 
histone modifications have critical roles in regulating gene expression. Gene expression is dependent on the presence of transcription factors, and mostly on the access of these transcription factors to transcription start sites. The chromatin structure surrounding the transcription start site, determined by the distance between individual nucleosomes comprised of DNA wrapped around histone octamers, is determined by both DNA methylation and histone modifications and determines accessibility of the DNA for transcription factors. DNA methylated at CpG sites in combination with 'silencing' histone modifications, including trimethylation of lysine 27 on histone $\mathrm{H} 3$ (H3K27me3), is associated with a closed chromatin structure with limited access for transcription factors to the DNA (illustrated in Rodenhiser et al (Rodenhiser and Mann, 2006)). Unmethylated DNA in combination with 'active' histone modifications, including acetylation of lysine 9 on histone $\mathrm{H} 3$ (H3K9Ac), is associated with an open chromatin structure, which permits gene transcription (Rodenhiser and Mann, 2006).

Given the recognised de-regulation of these epigenetic mechanisms in cancer (Lao and Grady, 2011; van Engeland et al, 2011), we investigated whether both global DNA methylation and histone modification patterns can be used to predict clinical outcome in rectal cancer patients enrolled in a well-defined, strictly qualitycontrolled (Klein Kranenbarg and van de Velde, 2002) clinical trial.

\section{MATERIALS AND METHODS}

Patient selection. Formalin-fixed paraffin-embedded (FFPE) specimens were collected from patients enrolled in the Dutch TME multicenter clinical trial (non-irradiated arm) between 1996 and 1999 with no evidence of disease after surgical resection and a median follow-up of 7 years. Patient characteristics are displayed in Table 1. Informed consent was obtained from all patients enrolled in the TME trial. The study was approved by the Medical Ethical Committee of the Leiden University Medical Center. Western IRB permission was obtained for assessment of patient specimens at John Wayne Cancer Institute. A pilot study was performed using 30 primary rectal tumour FFPE specimens, TNM tumour stages I $(n=10)$, II $(n=12)$ and III $(n=8)$, and 25 normal rectal tissues resected at least $5 \mathrm{~cm}$ away from the tumour. TNM tumour stages were defined according to the American Joint Committee on Cancer (AJCC) staging system (Edge, 2010).

For the validation study, a patient selection $(n=189)$ representative for the non-irradiated arm of the TME trial was made based on sex, age at randomisation, and circumferential margin involvement, with TNM tumour stages I $(n=53)$, II $(n=43)$, III $(n=85)$ and IV $(n=8) .53$ additional normal rectal tissues were collected, with 45 out of the 53 cases having matching primary tumour specimens included in the study. Histone modifications were assessed on 132 tumour tissues and 50 normal tissues included in the validation cohort of the LINE-1 study and present on a tissue microarray (described below). This study was performed according to the REMARK guidelines (McShane et al, 2005).

DNA extraction from FFPE specimens and quantification of DNA for methylation assays. Tumour areas on H\&E-stained sections of FFPE tumour specimens were identified and marked by a pathologist. From each patient block, two $7-\mu \mathrm{m}$ FFPE sections were deparaffinized and stained with haematoxylin, followed by needle microdissection of tumour areas. DNA was extracted using a proteinase- $\mathrm{K}$ based protocol as described previously (Tanemura et al, 2009) and quantified using a Quant-iT PicoGreen dsDNA kit (Molecular Probes, Eugene, OR, USA).

Bisulfite conversion and quantitative real-time PCR for methylation assays. For each sample, $200 \mathrm{ng}$ of DNA was
Table 1. Patient characteristics of the pilot and validation study groups

\begin{tabular}{|c|c|c|c|c|c|c|}
\hline & \multicolumn{2}{|c|}{$\begin{array}{c}\text { All patients } \\
\text { non-irradiated } \\
\text { arm TME trial } \\
(n=769)\end{array}$} & \multicolumn{2}{|c|}{$\begin{array}{l}\text { Pilot study } \\
\qquad(n=30)\end{array}$} & \multicolumn{2}{|c|}{$\begin{array}{c}\text { Validation } \\
\text { study } \\
(n=189)\end{array}$} \\
\hline & $n$ & (\%) & $n$ & (\%) & $n$ & (\%) \\
\hline \multicolumn{7}{|l|}{ Sex } \\
\hline Male & 488 & 63.5 & 16 & 53.3 & 129 & 68.3 \\
\hline Female & 281 & 36.5 & 14 & 46.7 & 60 & 31.7 \\
\hline
\end{tabular}

Age at randomisation

\begin{tabular}{|l|c|c|c|}
\hline Mean & 64.4 & 64.1 & 63.9 \\
Standard error & 0.405 & 2.300 & 0.811 \\
\hline
\end{tabular}

TNM stage

\begin{tabular}{|l|c|c|c|c|c|c|}
\hline I & 224 & 29.6 & 10 & 33.3 & 53 & 28.0 \\
II & 195 & 25.8 & 12 & 40.0 & 43 & 22.8 \\
III & 281 & 37.2 & 8 & 26.7 & 85 & 45.0 \\
IV & 56 & 7.4 & & & 8 & 4.2 \\
\hline
\end{tabular}

Circumferential margin

\begin{tabular}{|l|c|c|c|c|c|c|}
\hline Negative & 621 & 80.8 & 29 & 96.7 & 152 & 80.4 \\
Positive & 148 & 19.2 & 1 & 3.3 & 37 & 19.6 \\
\hline
\end{tabular}

Tumour location

\begin{tabular}{|l|c|c|c|c|c|c|}
\hline Rectum & 679 & 90.1 & 26 & 86.7 & 161 & 85.6 \\
Anal region & 54 & 7.2 & 3 & 10.0 & 20 & 10.6 \\
Other & 21 & 2.8 & 1 & 3.3 & 7 & 3.7 \\
\hline
\end{tabular}

Patient characteristics are shown for both the pilot and validation study groups. Patient selection for the pilot study was based on TNM stage. Patient selection for the validation study was based on availability of FFPE tissues and all listed variables, that is, sex, age at randomisation, TNM stage, circumferential margin involvement and tumour location. The validation study selection was representative for the entire non-irradiated patient cohort.

bisulfite-converted using the Epitect Bisulfite Kit (Qiagen, Valencia, CA, USA); converted DNA was eluted in $50 \mu$ l elution buffer. Both LINE-1 and Alu PCR-based assays have been described previously (Umetani et al, 2006a; Sunami et al, 2011b). Quantitative real-time PCR for LINE-1 sequences (according to the MIQE guidelines (Bustin et al, 2009)) was performed using universal primers and a locked nucleic acid (LNA) probe specific to the bisulfite-converted methylated or unmethylated LINE-1 consensus L1.2 sequence. Primer and probe sequences were as follows: LINE-1 forward 5'-GGGTTTATTTTATTAGGGAGTGT TAGA-3', LINE-1 reverse 5'-TCACCCCTTTCTTTAACTCAA A-3', LINE-1 FAM-M-Probe (LNA): $5^{\prime}-\mathrm{TG}+\mathrm{CG}+\mathrm{CGAGT}+$ CGAAG- $3^{\prime}$, LINE-1 FAM-U-Probe (LNA): $\quad 5^{\prime}-\mathrm{TG}+\mathrm{TG}+$ TGAG $+\mathrm{T}+\mathrm{T}+\mathrm{GAA}+\mathrm{GTAG}-3^{\prime}$. Thermal cycling reactions were as follows: hot start for $3 \mathrm{~min}$ at $95^{\circ} \mathrm{C}$, followed by 45 cycles of denaturing at $95^{\circ} \mathrm{C}(15 \mathrm{~s})$ and annealing/extension at $60^{\circ} \mathrm{C}$ (1 min). For Alu repeat sequences analysis, quantitative real-time PCR was performed as previously described (Umetani et al, 2006b). Primer and probe sequences specific for the Alu consensus sequence were as follows: Alu forward: $5^{\prime}$-GTTTGGTTAAT ATGGTGAAATT-3', Alu reverse: $5^{\prime}$-ATTCTCCTACCTCAACC-3', Alu FAM-M-Probe (LNA): $5^{\prime}-\mathrm{A}+\mathrm{AC}+$ GCGCGCCAC-3', Alu FAM-U-Probe (LNA): $5^{\prime}-\mathrm{AAC}+\mathrm{AC}+\mathrm{A}+\mathrm{CACCA}+\mathrm{CCA}-3^{\prime}$. Thermal cycling reactions were as described above for LINE-1, but with annealing/extension at $58{ }^{\circ} \mathrm{C}$.

Quantitative PCR reactions were run on a 384 CFX thermal cycler (BioRad, Hercules, CA, USA). A serial dilution of plasmids 
with either the methylated or the unmethylated sequence was used to generate standard curves for quantification. Triplicates of each sample (20 ng DNA per reaction) were run on the same plate, and mean copy numbers $(\mathrm{CN})$ were used for statistical analyses. Measurements were repeated when triplicates varied $>2 \mathrm{Cq}$ values. Controls used in both LINE-1 and Alu methylation assays were universally methylated DNA (UMC; Millipore, Billerica, MA, USA), universally unmethylated DNA obtained by repeated whole-genome amplification of PBL DNA (UUC; Repli-g kit; Qiagen) and peripheral blood lymphocytes. Specific methylated cell line controls for LINE-1 methylation assays were melanoma cell line M12 and for Alu methylation assays breast cancer cell line MCF-7. Methylation percentages were calculated as follows: methylation percentage $=\mathrm{CN}$ methylated/ $(\mathrm{CN}$ methylated $+\mathrm{CN}$ unmethylated $) \times 100 \%$.

Immunohistochemical staining and semi-automated scoring of histone modifications. Tumour and normal tissue FFPE blocks with enough tissue available were selected from patients enrolled in the non-irradiated arm of the Dutch TME clinical trial. Tumour cores from 496 patients and normal tissue cores (taken at least $5 \mathrm{~cm}$ away from the tumour) from 334 patients enrolled in the Dutch TME clinical trial were included to construct a tissue microarray (TMA). From each donor block, three $1-\mathrm{mm}^{2}$ tissue cores from strictly tumour or normal tissue (center) areas as marked by an experienced pathologist were punched and transferred into a recipient paraffin block using a TMA Master (3DHistech, Budapest, Hungary). $4.5 \mu \mathrm{m}$ tissue sections of the TMAs were cut and processed for immunohistochemical staining. TMA sections were stained using mouse anti-H3K27me3 (dilution $1: 200$; ab6002, Abcam, Cambridge, UK) or rabbit anti-H3K9Ac (dilution 1:600, ab8898, Abcam), using a standard IHC protocol (van Nes et al, 2011). Briefly, antigen retrieval was performed by heating the sections for $10 \mathrm{~min}$ at $95^{\circ} \mathrm{C}$ in a citrate buffer $(\mathrm{pH} 6.1$; $\mathrm{pH}$ low Target Retrieval Solution, Dako, Heverlee, Belgium) after deparaffinisation. Endogenous peroxidase was blocked by incubating the sections in a $0.3 \%$ solution of hydrogen peroxide (in PBS) for $20 \mathrm{~min}$. Sections were incubated with primary antibodies overnight (16h). Immunohistochemical staining was visualised using the Dako REAL EnVision Detection System, Peroxidase/ $\mathrm{DAB}+$, Rabbit/Mouse (Dako). Immunohistochemically stained tissue microarrays were scanned at $\times 20$ magnification on the Ariol system (Leica Microsystems, Rijswijk, The Netherlands). Expression of histone modifications was scored using the semiautomated Ariol system. Tumour areas were marked on the computer upon visual inspection, followed by training of the system to correctly identify positively stained and negative nuclei in the tissues, for each of the markers separately. Intensity of the staining was measured using the Ariol system and divided into three categories. The Ariol system was trained to count the number of cells in each category and to calculate a mean intensity score for each tissue core. Patients were divided into high- and low-intensity groups for each histone modification based on the median intensity score.

Statistical analysis. Statistical analysis of the data was performed by a biostatistician (H.P.) using statistical software SPSS version 20.0 (PASW Statistics, IBM Statistics, New York, NY, USA). Differences in mean LINE-1 methylation between the different TNM tumour stages were calculated using a Student's $t$-test (data were normally distributed). Univariate Cox regression analyses were performed to calculate differences in survival time and tumour recurrence between patients with a high or a low methylation index (LINE-1 and Alu) or staining intensity (histone modifications). Cutoff points for methylation groups were based on median intensity for the histone modifications and on median methylation index for LINE-1 or Alu. For histone modification analyses, only patients included in the LINE-1 validation study were used (tumours $n=132$, normal tissues $n=63$ ). For each
A
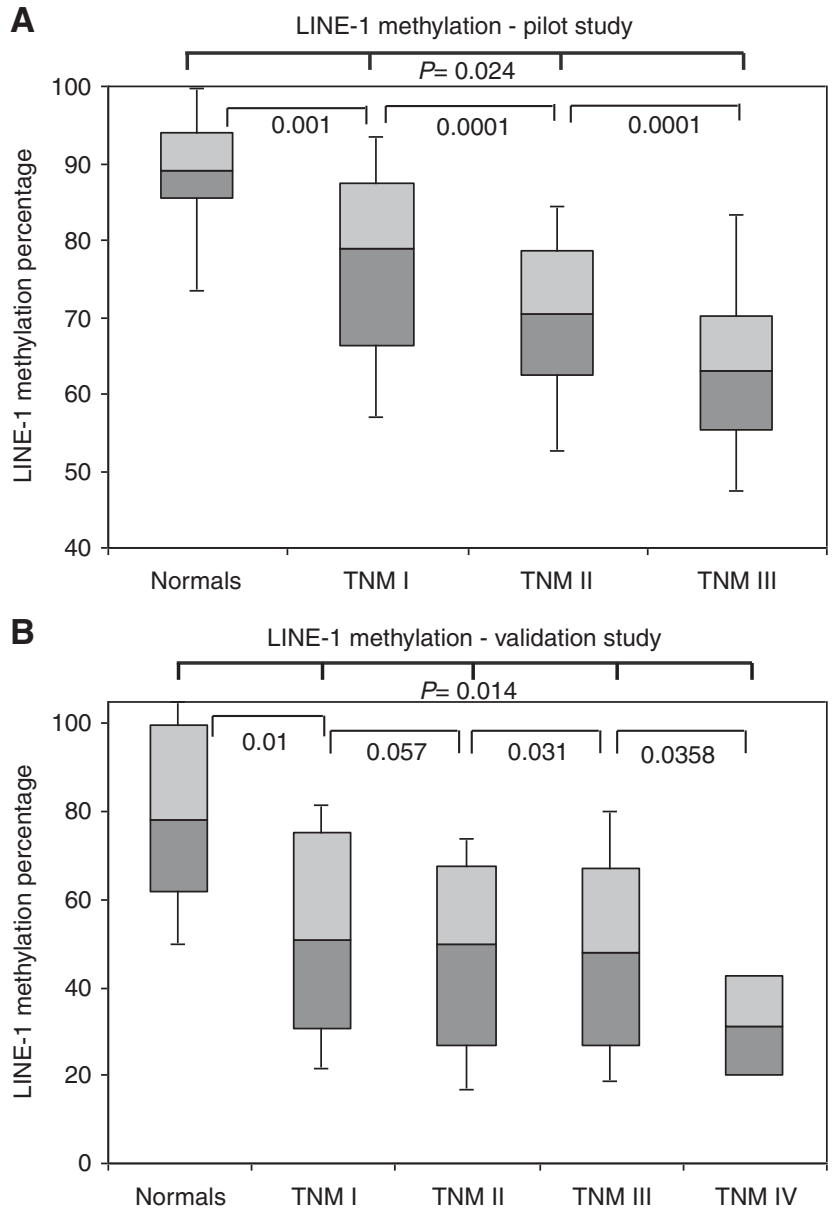

C

Alu methylation study

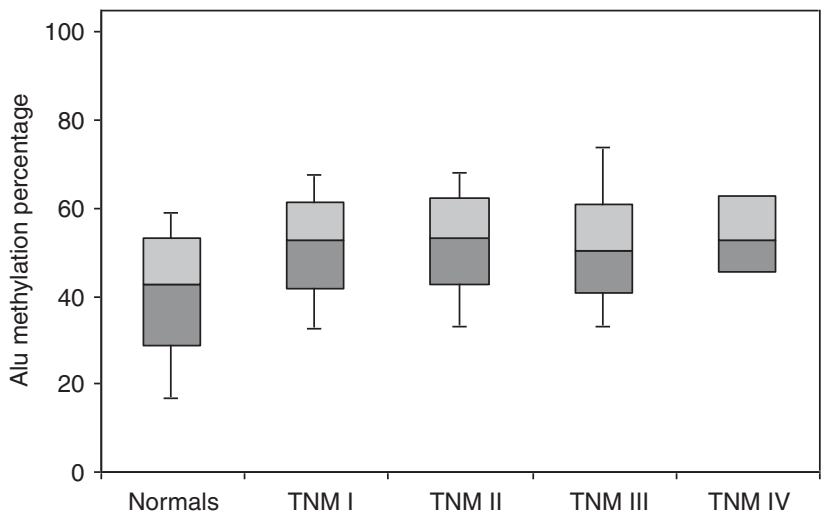

Figure 1. Mean LINE-1 methylation percentages according to TNM tumour stage in rectal cancer patients. Mean methylation percentages are shown for the different TNM tumour stages. Methylation percentages were calculated as follows: methylated copy number/ (methylated copies + unmethylated copies) $\times 100 \%$. (A) Mean LINE-1 methylation percentages are shown for different TNM tumour stages of the pilot study samples. TNM tumour stages are indicated as I, II and III, and normal samples are indicated as 'normal'. (B and C). Mean LINE-1 and Alu methylation percentages, respectively, are shown for different TNM tumour stages of the validation study samples. TNM tumour stages are indicated as I, II, III and IV, and normal samples are indicated as 'normal'.

patient, three cores (either three tumour or three normal cores) were scored, and mean intensity scores were calculated for each patient. Tumour cores with non-specific staining were excluded 


\begin{tabular}{|c|c|c|c|c|c|c|}
\hline \multirow[b]{2}{*}{ Variable } & \multicolumn{2}{|c|}{ Overall survival } & \multicolumn{2}{|c|}{ Local recurrence } & \multicolumn{2}{|c|}{ Distant recurrence } \\
\hline & HR $(95 \% \mathrm{Cl})$ & $\boldsymbol{P}$-value & HR $(95 \% \mathrm{Cl})$ & $\boldsymbol{P}$-value & HR $(95 \% \mathrm{Cl})$ & $\boldsymbol{P}$-value \\
\hline \multicolumn{7}{|c|}{ LINE-1 univariate analysis } \\
\hline LINE-1 methylation & $5.239(1.589-17.268)$ & 0.006 & $0.892(0.0 .23-34.803)$ & 0.951 & $9.943(2.476-30.028)$ & 0.003 \\
\hline \multicolumn{7}{|c|}{ LINE-1 multivariate analysis } \\
\hline $\begin{array}{l}\text { Age } \\
\text { Circumferential margin } \\
\text { TNM } \\
\text { Tumour location } \\
\text { LINE-1 methylation }\end{array}$ & $\begin{array}{l}1.028(0.997-1.061) \\
1.352(0.380-4.817) \\
1.570(0.814-3.028) \\
1.336(0.643-2.776) \\
4.568(1.359-15.351)\end{array}$ & $\begin{array}{l}0.080 \\
0.642 \\
0.178 \\
0.437 \\
0.014\end{array}$ & $\begin{array}{l}0.931(0.829-1.045) \\
0.513(0.164-2.839) \\
0.230(0.096-1.469) \\
0.346(0.123-1.896) \\
1.438(0.14-146.4)\end{array}$ & $\begin{array}{l}0.223 \\
0.962 \\
0.964 \\
0.974 \\
0.877\end{array}$ & $\begin{array}{l}0.957(0.913-1.003) \\
1.778(0.196-16.168) \\
1.907(0.607-5.995) \\
4.606(1.932-10.983) \\
9.576(4.443-47.131)\end{array}$ & $\begin{array}{l}0.068 \\
0.609 \\
0.269 \\
0.001 \\
0.001\end{array}$ \\
\hline \multicolumn{7}{|l|}{ Alu univariate analysis } \\
\hline Alu methylation & $1.269(0.681-2.361)$ & 0.453 & $1.093(0.154-7.763)$ & 0.929 & $1.897(0.689-5.227)$ & 0.215 \\
\hline \multicolumn{7}{|c|}{ Alu multivariate analysis } \\
\hline $\begin{array}{l}\text { Age } \\
\text { Circumferential margin } \\
\text { TNM } \\
\text { Tumour location } \\
\text { Alu methylation }\end{array}$ & $\begin{array}{l}1.391(1.016-1.904) \\
1.135(0.316-4.077) \\
1.209(0.697-2.097) \\
1.199(0.579-2.484) \\
0.996(0.979-1.014)\end{array}$ & $\begin{array}{l}0.039 \\
0.846 \\
0.500 \\
0.625 \\
0.690\end{array}$ & $\begin{array}{l}0.483(0.156-1.494) \\
1.978(0.699-5.604) \\
0.245(0.034-1.780) \\
0.203(0.029-1.543) \\
0.985(0.928-1.045)\end{array}$ & $\begin{array}{l}0.207 \\
0.080 \\
0.165 \\
0.989 \\
0.613\end{array}$ & $\begin{array}{l}0.696(0.451-1.072) \\
0.735(0.083-6.500) \\
1.462(0.573-3.731) \\
2.332(1.046-5.201) \\
0.980(0.952-1.010)\end{array}$ & $\begin{array}{l}0.100 \\
0.782 \\
0.427 \\
0.038 \\
0.185\end{array}$ \\
\hline
\end{tabular}

from the analyses $(n=13)$. Kaplan-Meier survival curves were made to visualise survival differences between high and low methylation groups (LINE-1) and high- and low-staining intensity (histone modifications), and significance was assessed using the log-rank test. All time-to-event variables were calculated from the date of surgery. Competing risk analyses were performed for cancer-specific survival and recurrence analyses in order to prevent overestimation of the number of events in each of the categories. Multivariate analyses using LINE-1 methylation or staining intensity of the histone modifications as continuous data were performed using the Cox proportional hazards model. Covariates entered in the multivariate model were age at time of surgery, circumferential margin, TNM stage and tumour location. For all analyses, a two-sided $P$-value of 0.05 or less was considered statistically significant. Data were censored when patients were alive or free of recurrence at their last follow-up date.

\section{RESULTS}

Methylation assay verification. To ensure a good performance and reproducibility of the LINE-1 and Alu methylation assays, we performed several quality checks. To verify the reproducibility of the assays, we ran a test set of eight samples for both Alu and LINE-1 methylation assays, which were independently repeated. Variation in methylation percentages between the two experiments was $0.1-1.6 \%$ for LINE- 1 and $0.1-1.2 \%$ for Alu. Control samples included on every plate showed minimal inter-plate variability $(<7 \%)$. Standard deviations were $6.6 \%$ for UMC and $3.8 \%$ for PBL in the LINE-1 methylation assays and $4.3 \%$ for MCF-7 and $5.4 \%$ for UMC in the Alu methylation assays. The limit of detection of this assay was as low as 100 copies of the respective plasmids in each reaction. Standard curves using plasmids of either the methylated or unmethylated sequences were highly reproducible for all assays, with $R^{2}$ values of 0.947 or higher between the duplicates on each of the individual plates. Taken together, the LNA-probe-based real-time PCR method used in this study proved to be very robust and reproducible.

LINE-1 methylation. The pilot study for LINE-1 methylation showed decreasing levels of methylation with increasing TNM tumour stage (Figure 1A). Normal tissues showed the highest LINE-1 methylation percentage compared with tumour tissues, with an average difference between matching tumour and normal samples $(n=8)$ of $14.2 \%$. Levels of LINE-1 methylation were significantly different across TNM tumour stages and between normal and tumour samples (normal $v s \mathrm{~T}, P=0.024$; across TNM tumour stages, $P<0.001$ ).

In the validation study, decreasing levels of methylation were observed with increasing TNM tumour stage $(P<0.001)$ (Figure 1B). The mean difference between the matching normal and tumour samples (45 out of 53 ) was $21.6 \%$, with a consistently higher methylation percentage in the normal samples. Univariate analyses showed low levels of LINE-1 methylation to be correlated with shorter survival $(P=0.006, \mathrm{HR}=5.169)$ and higher chance of distant recurrence $(P=0.003, \mathrm{HR}=9.943)$ in stage I and II rectal cancer patients (Table 2). Stage III and IV patients did not show any significant correlation between LINE-1 methylation and patient survival and tumour recurrence. Subsequent analyses were done with stage I and II patients only. Multivariate analyses of the validation study data showed LINE-1 methylation status to be an independent predictor of survival $(P=0.014$; HR 4.6) and distant recurrence $(P=0.001$; HR 9.6) in early-stage rectal cancer patients (Table 2).

Kaplan-Meier survival curves were generated (Figure 2A and B) to visualise differences in survival and recurrence between high and low LINE-1 methylation groups, based on median methylation 
A

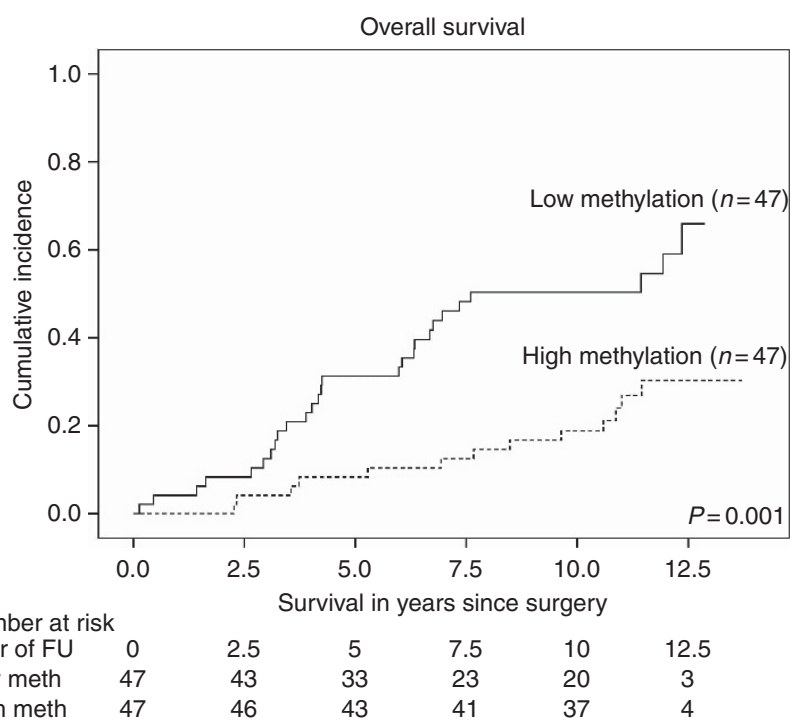

B

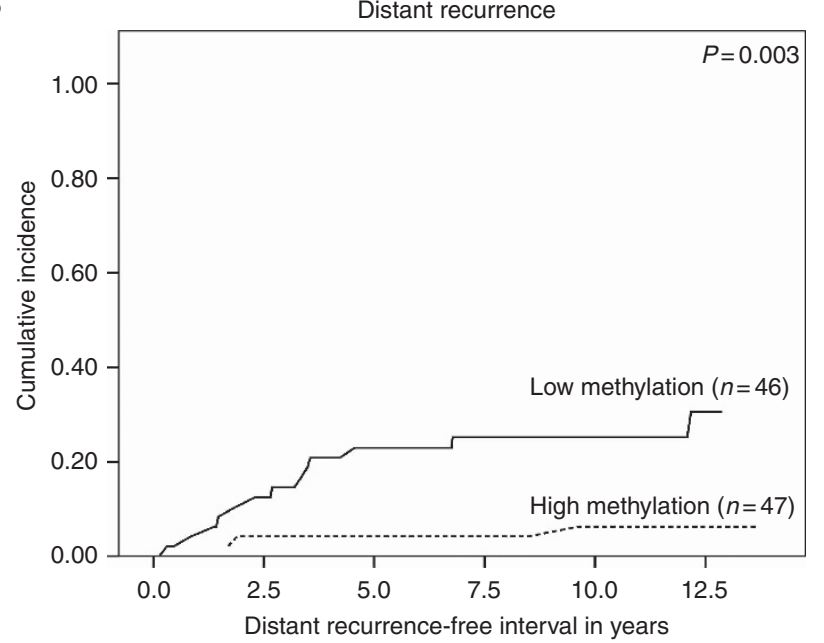

Number at risk

$\begin{array}{lcccccc}\text { Year of FU } & 0 & 2.5 & 5 & 7.5 & 10 & 12.5 \\ \text { Low meth } & 46 & 43 & 32 & 23 & 20 & 4 \\ \text { High meth } & 47 & 46 & 43 & 41 & 37 & 4\end{array}$

Figure 2. Kaplan-Meier curves of stage I and II rectal cancer patients by LINE-1 methylation status. Kaplan-Meier curves were made to visualise differences in survival and recurrence between patients with high and low LINE-1 methylation status. Log-rank tests were performed to calculate the difference between the low and high LINE-1 methylation groups. Survival times were calculated as time from surgery till an event (death or recurrence, respectively). (A) KaplanMeier curves showing overall survival of the high and low methylation groups based on LINE-1 methylation status. Patients at risk are displayed for each of the groups. (B) Kaplan-Meier curves showing distant recurrence in the high and low methylation groups based on LINE-1 methylation status. Patients at risk are displayed for each of the groups.

percentage $(57.4 \%)$ of stage I and II patients in the validation study. The log-rank test showed that patients with low-LINE-1 methylation have shorter survival times and a higher chance of tumour recurrence than patients with a higher methylation percentage. Significant differences were observed for overall survival $(P=0.006)$, overall recurrence $(P=0.0017)$ and distant recurrence-free survival $(P=0.003)$. No difference was found for local recurrence $(P=0.95)$, which can be explained by the fact that survival is mainly determined by distant metastases rather than local recurrences. The multivariate analyses showed that patients with a low level of LINE-1 methylation have a nine-fold higher chance of distant recurrence of the tumour and a five-fold lower chance of survival than patients with a high LINE-1 methylation level (Table 2). No correlation was found between LINE-1 methylation and lymphocyte infiltration $(P=0.217)$, a factor known to impact clinical outcome in colorectal cancer.

Our data showed that LINE-1 methylation status was prognostic of disease outcome, but Alu methylation was not. Chi-square $(P=0.38)$ and Pearson's correlation $(P=-0.306)$ analyses confirmed that Alu methylation and LINE-1 methylation indeed did not correlate. Similarly, in multivariate analyses, the interaction between Alu and LINE-1 methylation did not show significant correlation with survival $(P=0.23)$. This confirmed that Alu and LINE-1 methylation did not have a similar effect on patient survival and tumour recurrence in this set of rectal cancer patients, suggesting that LINE-1 may be involved in specific tumour progression events that affect disease outcome in rectal cancer, rather than reflecting a genome-wide methylation status.

Alu methylation. To investigate if LINE-1 methylation indeed did not just represent genome-wide methylation status, we studied methylation of Alu repeat sequences in the same patient cohort. The levels of Alu methylation were not significantly different between normal and tumour tissues (pilot study; $P=0.24$ ) or between patients with or without a recurrence (pilot study; $P=0.27)$. Alu methylation levels did not differ between the different TNM tumour stages in either the pilot $(P=0.11)$ or the validation study $(P=0.73$; Figure $1 C)$. The mean difference in Alu methylation percentage between normal and matching tumour tissues was $1.03 \%$ in the validation series. Survival analyses on the data in the validation series did not show any significant differences using a cutoff based on median Alu methylation percentage $(60 \%)$. Neither overall survival nor overall recurrence did show differences between the groups $(P=0.65$ and $P=0.31$, respectively). Selection of stage I and II patients only, as described for the LINE-1 methylation studies, did not change outcomes of either survival or multivariate analyses (Table 2).

Histone modifications. Histone modifications $\mathrm{H} 3 \mathrm{~K} 27 \mathrm{me} 3$ and H3K9Ac were assessed by IHC on TMA sections. Only patients included in the LINE-1 validation study were used for histone modification analyses (tumours $n=132$, normal tissues $n=63$ ). Semi-automated analyses using the Ariol System yielded intensity scores for each of the individual tumour cores. Correct identification of positive and negative cells using the Ariol system is shown in Figure 3. Mean intensity scores of three tumour tissue cores were calculated for each patient and used for survival analyses. Patients were divided into high and low intensity groups for each histone modification based on the median intensity score. H3K27me3 intensity scores ranged from 0 to 63.14, H3K9Ac intensity scores ranged from 0 to 67.84. Median intensity scores were 50.59 in normal tissues and 48.20 in tumour tissues for H3K9Ac $(P=0.053)$ and 49.41 in normal tissues and 51.77 in tumour tissues for H3K27me3 $(P=0.002)$. H3K9Ac and H3K27me3 intensities in tumour tissues show an inverse correlation, with $P=0.024$.

Both H3K27me3 $(P=0.049)$ and H3K9Ac $(P=0.14)$ showed differences in overall survival between high- and low-intensity groups (Figure 4A and B, respectively). For H3K27me3, low-intensity scores were correlated with worse overall survival, whereas, for H3K9Ac, high intensity was correlated with worse overall survival. As for tumour recurrence, histone modifications were correlated with local recurrence with $\mathrm{H} 3 \mathrm{~K} 27 \mathrm{me} 3(P=0.001)$ and H3K9Ac $(P=0.084)$ but not with distant recurrence with H3K27me3 $(P=0.172)$ and H3K9Ac $(P=0.291)$. Multivariate analyses including LINE-1 methylation and histone modification intensities as continuous variables showed that LINE-1 methylation is a dominant factor in determining clinical outcome, as 
A

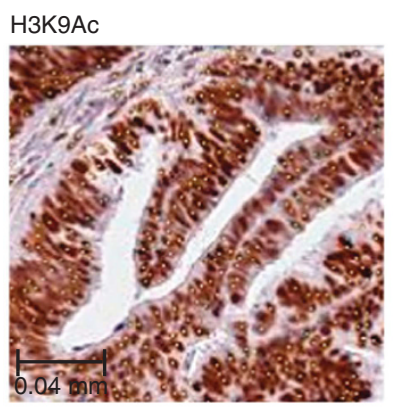

D

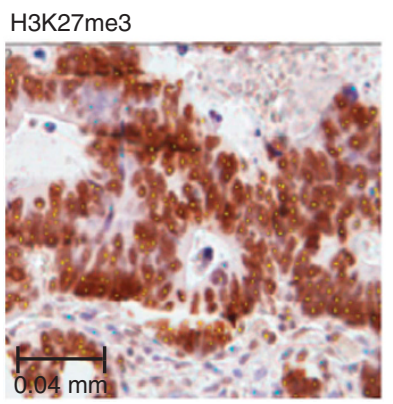

B

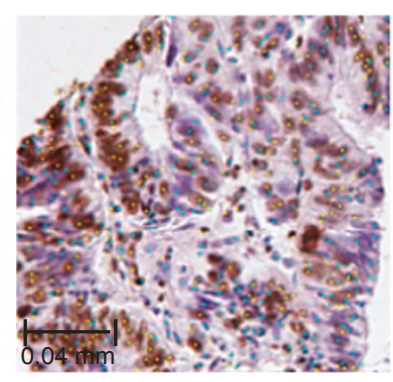

E

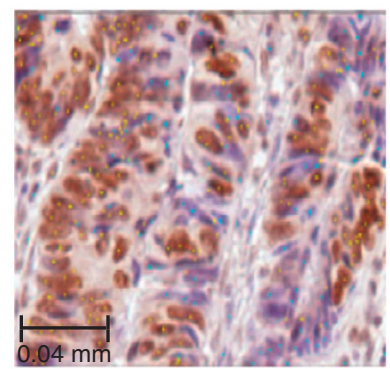

C

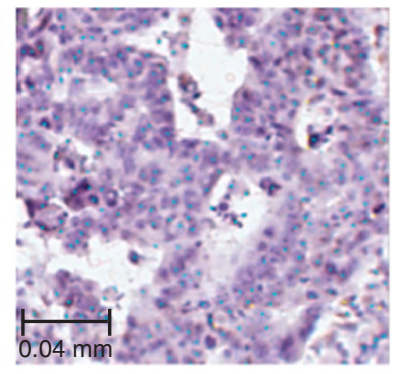

$\mathbf{F}$

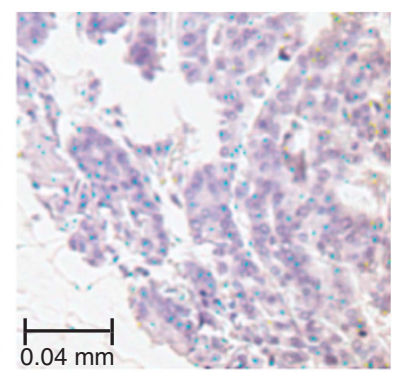

Figure 3. Identification of positively stained and negative tumour cells using the Ariol system. The Ariol system trainer overlay shows correct identification of positive (yellow dots) and negative (blue dots) cells on tumour cores. TMA slides were scanned using a $\times 20$ magnification. Shown for both H3K9Ac and H3K27me3 are highly positive tumour cores (A and D), tumour cores with both positive and negative cells (B and E) and negative tumour cores ( $\mathbf{C}$ and $\mathbf{F}$ ). The Ariol system was trained to identify positive and negative cells for each individual marker.

adding histone modification intensities did not improve the multivariate model. LINE-1 methylation showed correlation with overall survival (with addition of $\mathrm{H} 3 \mathrm{~K} 27 \mathrm{me} 3 \quad P=0.062$ and H3K9Ac $P=0.15$ ) and distant recurrence-free survival (with addition of H3K27me3 $P=0.019$ and H3K9Ac $P=0.018$ ), but not with local recurrence-free survival (with addition of H3K27me3 $P=0.82$ and H3K9Ac $P=0.97$ ).

In order to further study the relationship between LINE-1 methylation and histone modifications, we stratified histone modifications according to LINE-1 methylation levels. H3K27me3 intensity was found to significantly correlate with overall survival $(P=0.020)$ and local recurrence-free survival $(P=0.017)$ only when LINE-1 methylation was low (Figure 5A and $\mathrm{C}$, respectively). Within this patient subset with low LINE-1 methylation, patients with high $\mathrm{H} 3 \mathrm{~K} 27$ me3 intensity scores show better survival rates than patients with low presence of H3K27me3. High H3K27 methylation could have a 'protective' function in the cells, preventing deregulated gene expression when DNA methylation is absent. H3K27me3 did not show any differences between high- and low-intensity groups when LINE-1 methylation was high, with overall survival $(P=0.37)$ and local recurrence-free survival $(P=0.28)$, again indicating that LINE-1 methylation is a dominant factor determining clinical outcome in this patient group. Uni- and multivariate analyses for $\mathrm{H} 3 \mathrm{~K} 27 \mathrm{me} 3$ also showed statistically significant differences between high and low stainingintensity groups when LINE-1 methylation was low, both for overall survival (univariate $P=0.024$, multivariate $P=0.001$ ) and for local recurrence-free survival (univariate $P=0.046$, multivariate $P=0.016$ ) (Table 3 ). Stratifying H3K27me3 intensity scores according to Alu methylation status did not show any significant differences (Figure 5B and D).

$\mathrm{H} 3 \mathrm{~K} 9 \mathrm{Ac}$ intensity correlated with local recurrence-free survival $(P=0.030)$ only when LINE-1 methylation was high (Figure $5 \mathrm{E}$ ). The presence of $\mathrm{H} 3 \mathrm{~K} 9$ acetylation in combination with high levels of DNA methylation could affect disease outcome through activation of aberrant gene expression. H3K9Ac did not show any differences between high- and low-intensity groups when LINE-1 methylation was low, with overall survival $(P=0.83)$ and local recurrence-free survival $(P=0.68)$. Univariate analyses showed a trend for H3K9Ac, when LINE-1 methylation was high, with local recurrence-free survival $(P=0.066)$ (Table 3). Unfortunately, in multivariate analyses, this trend was no longer observed. H3K9Ac did not show a significant correlation with overall survival in either uni- or multivariate analyses. Stratifying H3K9Ac intensity according to Alu methylation status did not show any significant differences (Figure 5F).

\section{DISCUSSION}

The results presented in this study show that LINE-1 methylation should be regarded as an independent prognostic biomarker in early-stage rectal cancer. LINE-1 methylation was assessed using quantitative PCR after needle microdissection of tumour tissue areas, which were carefully marked by an rectal cancer pathologist. Tumour tissue extracted using needle microdissection, in contrast to laser capture microdissection, may include more stromal tissue, including inflammatory cells. We therefore selected only tumour areas with $>80 \%$ tumour epithelial cells, thereby minimising the amount of stroma included in these assays. Although previous reports showed an association of lymphocytic infiltrates with clinical outcome (Nagtegaal et al, 2001) in colorectal cancer, in our rectal cancer study cohort we did not find a correlation between the amount of lymphocytic infiltrate and LINE-1 methylation that could influence our analyses. Therefore, it is not likely that our findings are influenced by stroma or infiltrating lymphocytes. In addition, Irahara et al have shown, by direct comparison, that LINE-1 methylation levels are comparable between needle microdissected and laser capture microdissected tumour tissues, indicating that the effect of contaminating cells on LINE-1 methylation is indeed minimal (Irahara et al, 2010). BRAF mutation and MSI status were not determined in this study 


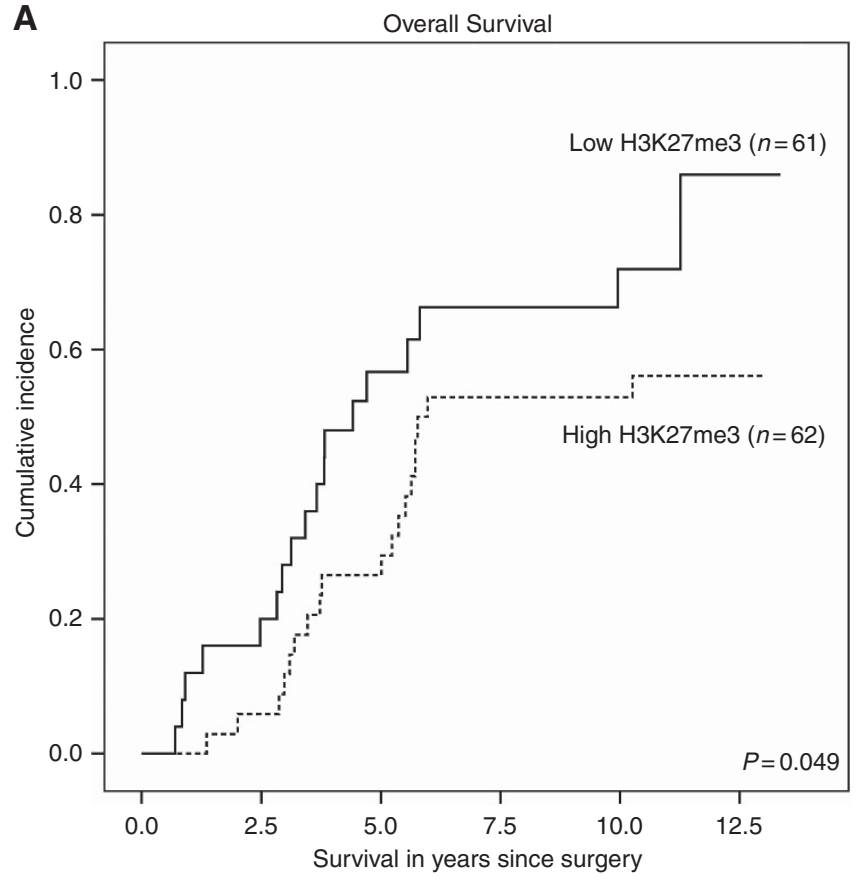

B

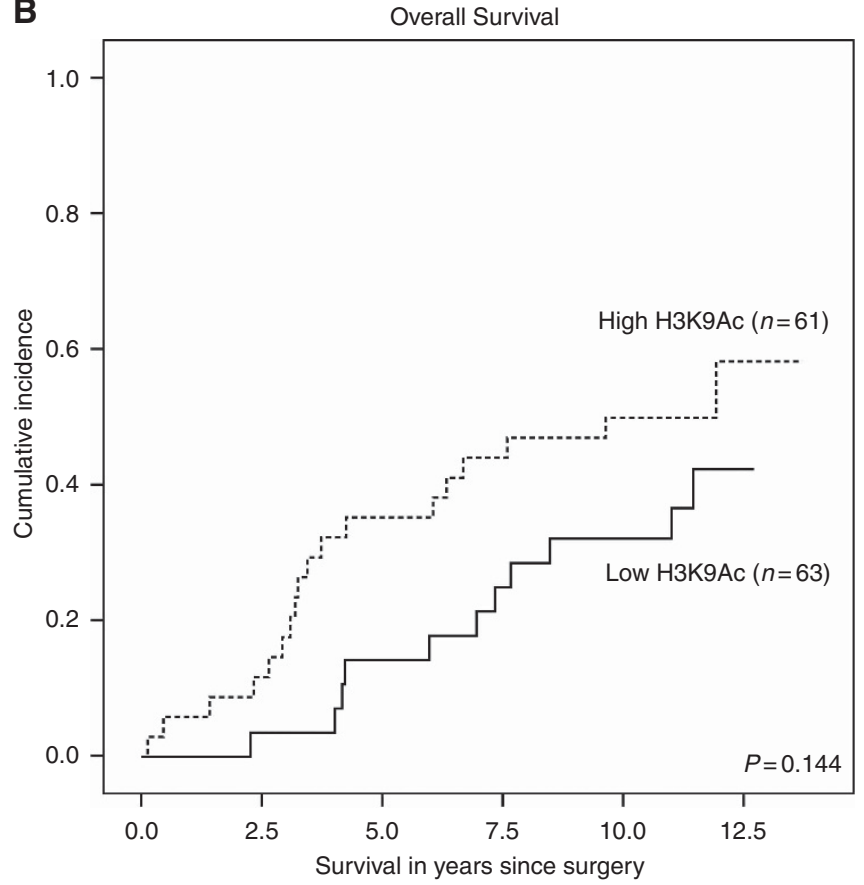

Figure 4. Kaplan-Meier curves of histone modifications H3K27me3 and H3K9Ac by expression levels. Kaplan-Meier curves were made to visualise differences in survival and recurrence between patients with high and low expression of H3K27me3. Log-rank tests were performed to calculate the difference between the low and high H3K27me3 expression groups. Survival times were calculated as time from surgery till an event (death or recurrence). (A) Kaplan-Meier curves showing overall survival of the high and low methylation groups based on H3K27me3 expression. (B) Kaplan-Meier curves showing overall survival in the high and low methylation groups based on H3K9Ac expression.

cohort, as the prevalence of BRAF mutations (around 2\%; (Gaedcke et al, 2010; Derbel et al, 2013)) and MSI (around 2\%; (Slattery et al, 2009)) is very low in rectal cancer. The impact of these markers on clinical outcome in multivariate analyses would therefore be negligible.
Because we wanted a rapid, robust, high-throughput and highly sensitive assay, we chose to use a quantitative real-time PCR assay instead of pyrosequencing to measure LINE-1 methylation. Pyrosequencing relies on PCR amplification of the region of interest, followed by sequencing of this PCR-amplified product. According to Nelson et al (2011) and Irahara et al (2010) pyrosequencing of LINE-1 sequences typically includes 3-6 CpG sites at the $5^{\prime}$-end of LINE- 1 sequences, which is comparable to the number of CPG sites included in the quantitative real-time PCR assay conducted in this study. Also, as suggested in Figure 1 of the pyrosequencing analysis by Irahara et al (2010), the methylation percentages of individual CpG sites measured with the LINE-1 pyrosequencing assay seem very similar within one sample. Therefore, measuring the three CpG sites at once using the qPCR method, instead of measuring individual $\mathrm{CpG}$ sites by pyrosequencing, is representative. In addition, for survival analyses conducted in this study, the median methylation percentage was used to divide the patients into high- and low-risk groups. As described by Irahara et al (2010), the average of the relative amounts of methylated cytosines found using pyrosequencing was used as overall LINE-1 methylation level in each sample, which is a similar approach as used with our qPCR data. Pyrosequencing information would probably result in a lower median methylation percentage, as hemimethylated CpGs can be accurately measured. However, this would yield a lower LINE-1 methylation percentage for every patient in our cohort, and we expect this will not affect the distribution of the patients into the two groups based on the median LINE-1 methylation percentage. Therefore, we are confident the qPCR method used in this study was a valid method to study LINE-1 methylation.

In our study cohort, stage III and IV patients did not show a significant correlation of LINE-1 methylation with survival and recurrence, most likely because other clinical factors such as nodal status and circumferential resection margin involvement have a significant role in advanced stage cancers, overpowering the effect of an earlier event in tumorigenesis. Epigenomic aberrations in tumours of stage I and II patients without invasive tumour characteristics, however, may be associated with the development of aggressive tumours and have clinical relevance for risk stratification. LINE-1 methylation has been described as an early-stage tumour marker in previous studies (Sunami et al, 2011a; Murata et al, 2013).

Methylation of LINE-1 and Alu repeats have both been used as surrogate markers for genome-wide methylation status (Weisenberger et al, 2005). On the basis of the general hypothesis that tumorigenesis is associated with genome-wide DNA hypomethylation and locus-specific hypermethylation of individual CpG islands (Cho et al, 2007; Esteller, 2007), we expected to see a decrease in both Alu and LINE-1 methylation levels with increasing TNM tumour stage in rectal cancer tissues. However, as we showed here that Alu methylation, in contrast with LINE-1, did not change with tumour progression and that methylation levels of LINE-1 and Alu did not correlate, our results suggest a more specific effect of LINE-1 methylation in early rectal tumours instead of reflecting a genome-wide methylation status. Other studies also suggest a specific role for LINE-1 methylation in tumorigenesis, whereas other repetitive sequences such as Alu repeats remain equally methylated (Perrin et al, 2007). Active LINE-1 sequences, an estimated 30-60 copies per cell, have retrotranspositional activity (Sassaman et al, 1997) and can translocate to other (non-)coding regions (Sellis et al, 2007; Beck et al, 2010, 2011), thereby contributing to (epi)genetic variation (Ogino et al, 2008; de Andrade et al, 2011). In normal cells, retrotransposition of repeat sequence elements is repressed by methylation of cytosine residues (Yoder et al, 1997). Reintegration of LINE-1 retrotransposons can disrupt genes and regulate their expression (Matlik et al, 2006; Chow et al, 2010), as described for 
A

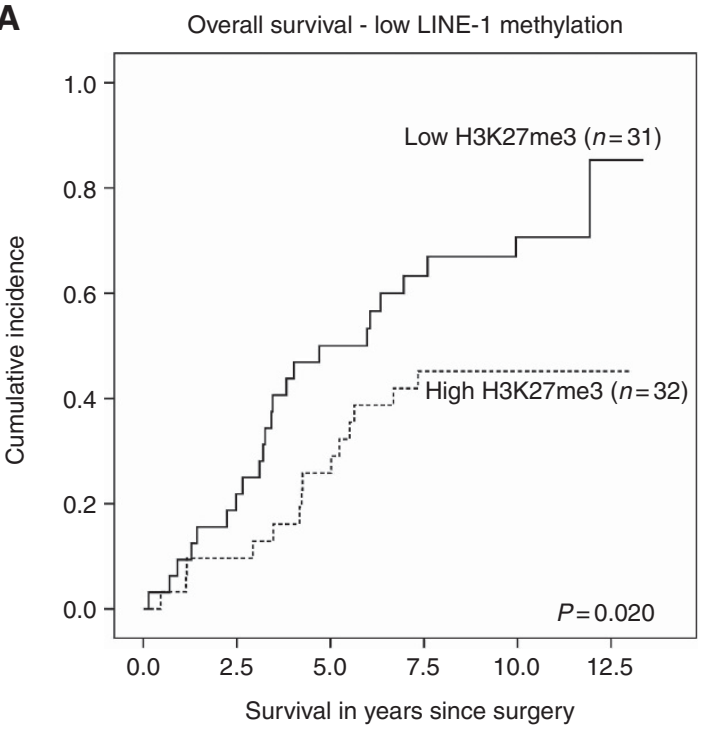

C

Local recurrence-free survival - low LINE-1 methylation

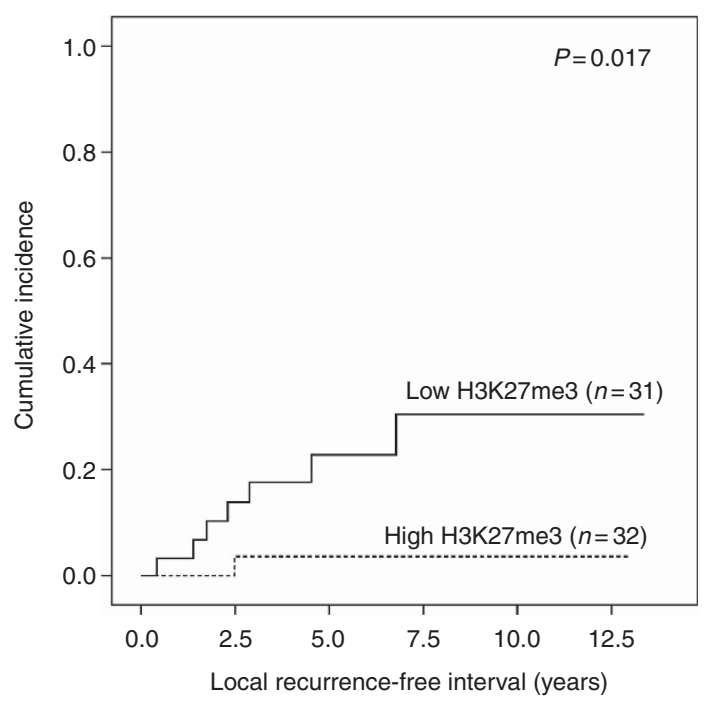

E

Local recurrence-free survival - high LINE-1 methylation

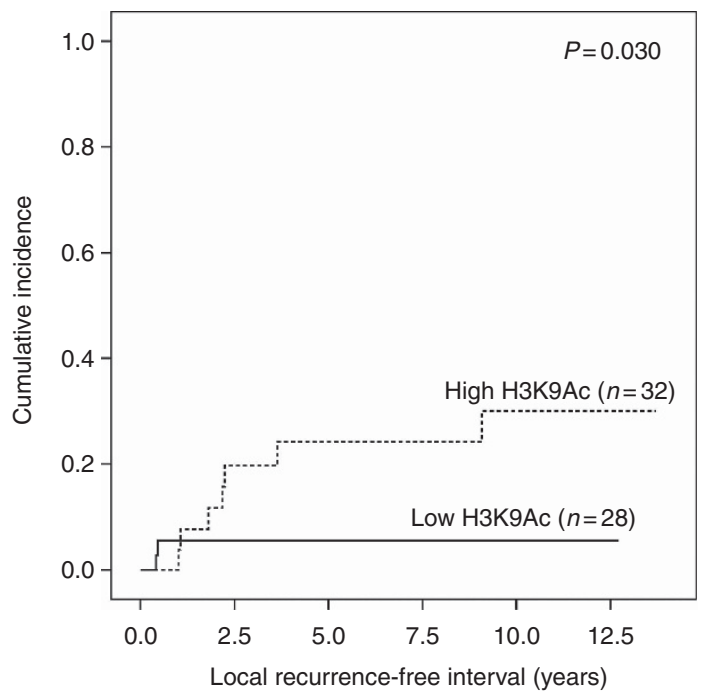

B

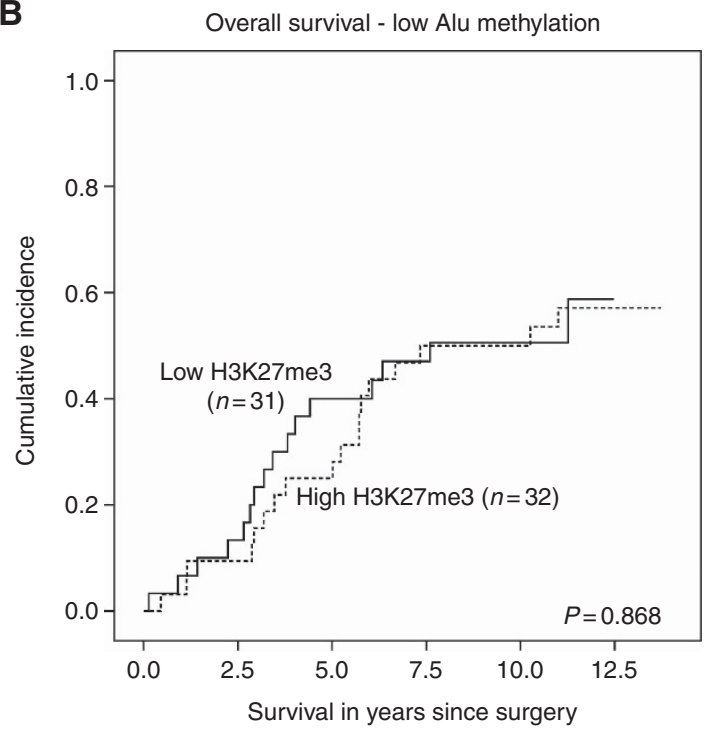

D

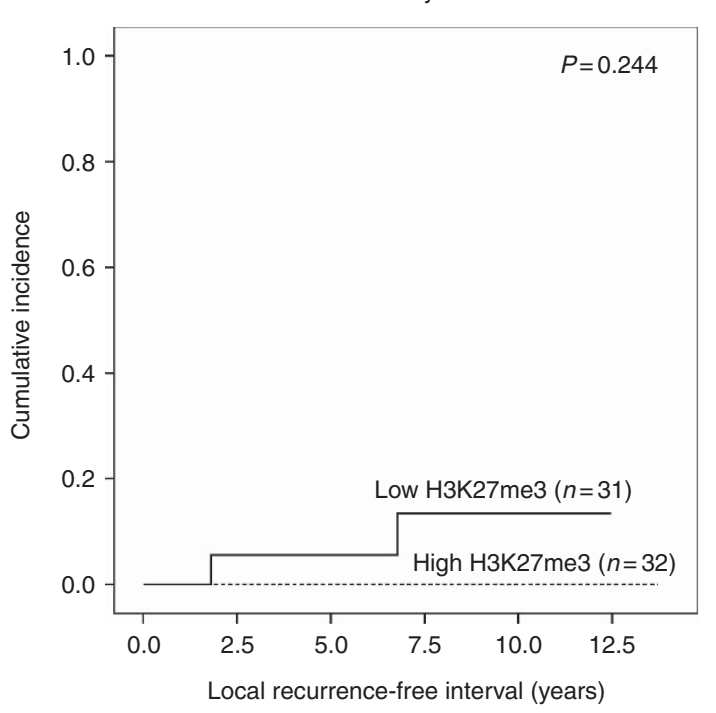

$\mathbf{F}$

Local recurrence-free survival - high

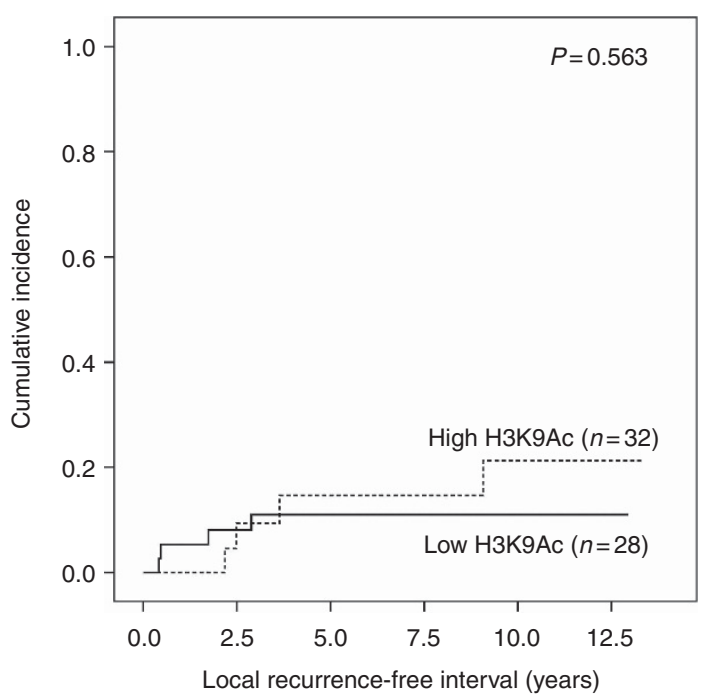


APC in colon cancer (Miki et al, 1992). Using the genome vicinity information of the full-length active LINE-1 sequences provided in the L1base database (Max-Planck Institute Berlin and University of Würzburg (Penzkofer et al, 2005)), we found that several LINE-1 sequences are located near or in (intronic) gene regions. As neighbouring DNA methylation patterns can influence nearby promoter regions (Wang et al, 2011; Zhang et al, 2012) or longer stretches of DNA, up to $2 \mathrm{~kb}$ distant (Irizarry et al, 2009), demethylation of LINE-1 sequences might therefore represent demethylation events of the coding gene promoters in their vicinity and hence influence expression of genes in these regions, translating into worse clinical outcome for the patient. This hypothesis was further supported by Hur et al (2013), who showed that specific LINE-1 sequences residing in intronic regions of several proto-oncogenes were hypomethylated in metastatic tissues compared with the corresponding primary tumours, indicating that differentially methylated LINE-1 sequences can indeed influence progression of colorectal tumours.

Recent articles by Goel et al (2010) and Ogino et al (2013) describe that LINE-1 hypomethylation is correlated with shorter survival, independent of clinical or molecular features, in non-MSI (microsatellite instability) familial tumours. Mechanisms predisposing patients with a family history of (and thus early-onset) colorectal cancer, but with no evidence of MSI or other molecular features associated with familial cancers, for the development of a tumour are still unknown. The authors of both articles conclude that LINE-1 hypomethylation might be an important factor promoting tumour growth in familial cases of (MSS) colorectal cancers. In our study, consisting of MSS rectal cancer patients, we also show a significant prognostic role for LINE-1 hypomethylation in determining clinical outcome. Together, these studies suggest that LINE-1 methylation might represent a frequently deregulated regulatory epigenetic mechanism that might promote primary tumour progression and metastasis of rectal tumours. Hence, LINE-1 methylation may potentially serve as a new biomarker to identify high-risk patients. Future studies will have to be performed to validate the clinical utility of LINE-1 methylation in rectal cancer.

The histone modifications reported in our study also support the clinical impact of genome-wide changes in epigenetic modifications in rectal cancer patients. On the basis of our current knowledge about the interplay between histone modifications and DNA methylation, we hypothesised that silencing modification H3K27me3 should follow the same pattern as LINE-1 methylation, as both epigenetic mechanisms are involved in silencing of gene expression. Indeed, low expression of $\mathrm{H} 3 \mathrm{~K} 27 \mathrm{me} 3$ was associated with worse survival. The finding that $\mathrm{H} 3 \mathrm{~K} 27 \mathrm{me} 3$ was associated with clinical outcome only when LINE-1 methylation is low supports the generally accepted hypothesis that DNA methylation and histone modifications together control gene expression and thereby define the cellular phenotype. Activating histone modification H3K9Ac was expected to show opposite results, as presence of this histone modification will lead to (aberrant) activation of gene expression. Indeed, high expression of H3K9Ac was associated with a shorter survival and higher chance of recurrence compared with patients with low H3K9Ac expression. As both H3K27me3 and H3K9Ac expressions only correlate with LINE-1 methylation and not with Alu methylation, we again conclude that LINE-1 methylation may be involved in specific tumour progression events in rectal cancer, rather than reflecting genome-wide methylation

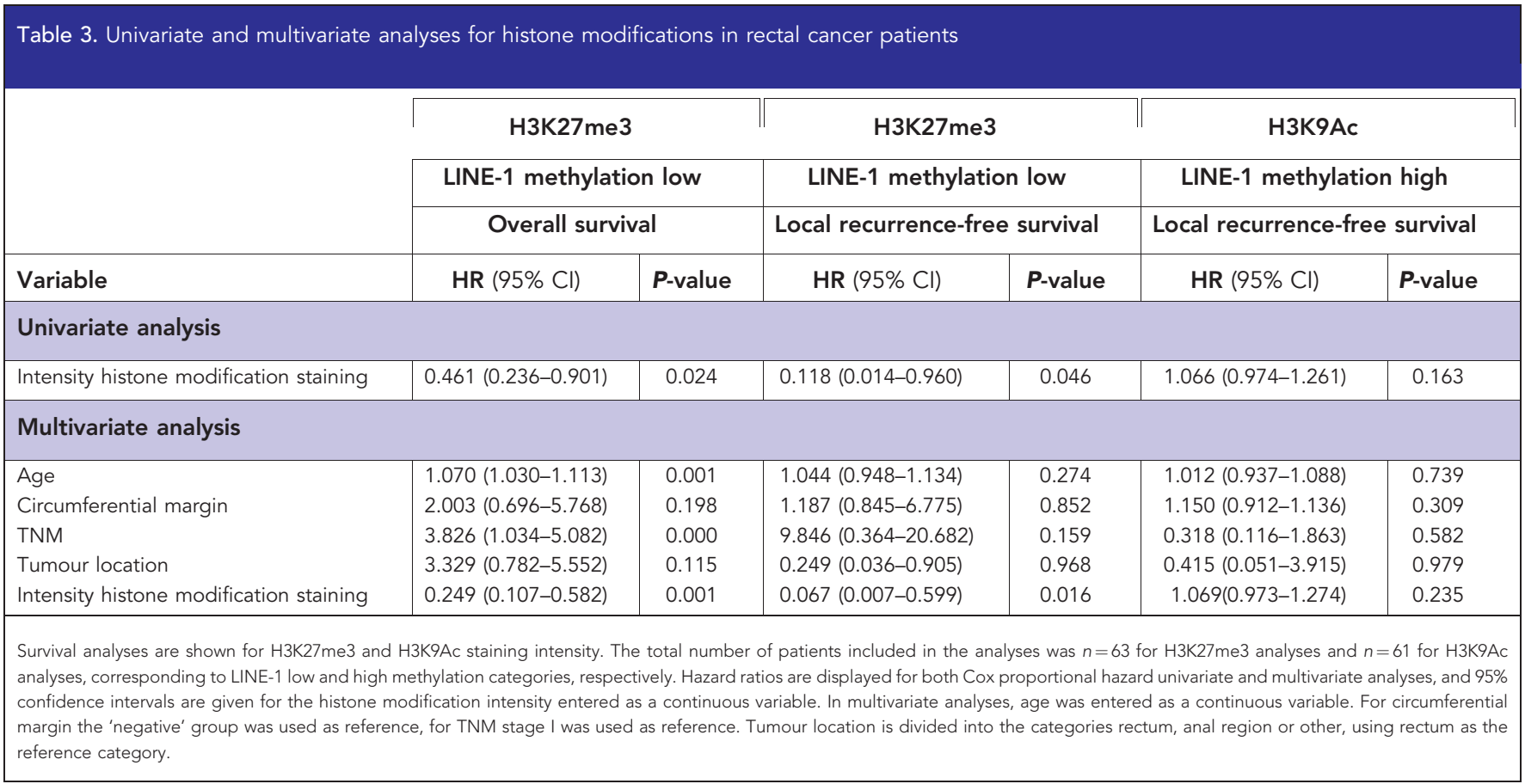

Figure 5. Kaplan-Meier curves of histone modifications H3K27me3 and H3K9Ac according to LINE-1 or Alu methylation levels. Kaplan-Meier curves were made to visualise differences in survival and recurrence between patients with high and low expression of H3K27me3 and H3K9Ac. Log-rank tests were performed to calculate the difference between the low and high H3K27me3 or H3K9Ac expression groups, respectively. Survival times were calculated as time from surgery till an event (death or recurrence). (A) Overall survival based on H3K27me3 expression in the LINE-1 methylation low group. (B) Overall survival based on H3K27me3 expression in the Alu methylation low group. (C) Local recurrence-free survival based on H3K27me3 expression in the LINE-1 methylation low group. (D) Local recurrence-free survival based on $\mathrm{H} 3 \mathrm{~K} 27 \mathrm{me} 3$ expression in the Alu methylation low group. (E) Local recurrence-free survival based on H3K9Ac expression in the LINE-1 methylation high group. (F) Local recurrence-free survival based on H3K9Ac expression in the Alu methylation high group. 
status in these tumours. Histone modifications H3K27me3 and $\mathrm{H} 3 \mathrm{~K} 9 \mathrm{Ac}$ intensity scores can further subdivide rectal cancer patients into high- or low-risk groups when stratified according to LINE-1 methylation status. This indicates that LINE-1 methylation and histone modifications work closely together in determining gene expression and hence tumour progression and ultimately clinical outcome.

In conclusion, we have shown in this study that LINE-1 methylation is an independent predictor of survival and recurrence in early-stage rectal cancer. Expression of histone modifications $\mathrm{H} 3 \mathrm{~K} 9 \mathrm{Ac}$ and H3K27me3 further support an active role in rectal cancer progression for LINE-1 methylation. Further research should be conducted to investigate the exact function of LINE-1 elements, and their influence on neighbouring genes, in order to better understand the complex nature of the rectal tumorigenic process. We show here that methylation of LINE-1 repeat sequences can be used as a biomarker to distinguish rectal cancer patients with a high risk of distant recurrence at an early stage, and therefore has potential to complement the current TNM staging system.

\section{ACKNOWLEDGEMENTS}

This work was supported by grant number 1R01CA171767-01A1 from the National Institute of Health, National Cancer Institute (DSBH). This study was also supported by the Leslie and Susan Gonda (Goldschmied) Foundation (Los Angeles, CA) and Ruth and Martin H Weil Fund (Los Angeles, CA; DSBH).

\section{REFERENCES}

Bae JM, Shin SH, Kwon HJ, Park SY, Kook MC, Kim YW, Cho NY, Kim N, Kim TY, Kim D, Kang GH (2011) ALU and LINE-1 hypomethylations in multistep gastric carcinogenesis and their prognostic implications. Int J Cancer 131(6): 1323-1331.

Beck CR, Collier P, Macfarlane C, Malig M, Kidd JM, Eichler EE, Badge RM, Moran JV (2010) LINE-1 retrotransposition activity in human genomes. Cell 141(7): 1159-1170.

Beck CR, Garcia-Perez JL, Badge RM, Moran JV (2011) LINE-1 elements in structural variation and disease. Annu Rev Genomics Hum Genet 12 $187-215$.

Burwinkel B, Kilimann MW (1998) Unequal homologous recombination between LINE-1 elements as a mutational mechanism in human genetic disease. J Mol Biol 277(3): 513-517.

Bustin SA, Benes V, Garson JA, Hellemans J, Huggett J, Kubista M, Mueller R, Nolan T, Pfaffl MW, Shipley GL, Vandesompele J, Wittwer CT (2009) The MIQE guidelines: minimum information for publication of quantitative real-time PCR experiments. Clin Chem 55(4): 611-622.

Chen JM, Stenson PD, Cooper DN, Ferec C (2005) A systematic analysis of LINE-1 endonuclease-dependent retrotranspositional events causing human genetic disease. Hum Genet 117(5): 411-427.

Cho NY, Kim BH, Choi M, Yoo EJ, Moon KC, Cho YM, Kim D, Kang GH (2007) Hypermethylation of CpG island loci and hypomethylation of LINE-1 and Alu repeats in prostate adenocarcinoma and their relationship to clinicopathological features. J Pathol 211(3): 269-277.

Chow JC, Ciaudo C, Fazzari MJ, Mise N, Servant N, Glass JL, Attreed M, Avner P, Wutz A, Barillot E, Greally JM, Voinnet O, Heard E (2010) LINE-1 activity in facultative heterochromatin formation during $\mathrm{X}$ chromosome inactivation. Cell 141(6): 956-969.

de Andrade A, Wang M, Bonaldo MF, Xie H, Soares MB (2011) Genetic and epigenetic variations contributed by Alu retrotransposition. $B M C$ Genomics 12: 617

de Maat MF, Umetani N, Sunami E, Turner RR, Hoon DS (2007) Assessment of methylation events during colorectal tumor progression by absolute quantitative analysis of methylated alleles. Mol Cancer Res 5(5): 461-471.

de Maat MF, van de Velde CJ, Benard A, Putter H, Morreau H, van Krieken JH, Meershoek Klein-Kranenbarg E, de Graaf EJ, Tollenaar RA, Hoon DS (2010) Identification of a quantitative MINT locus methylation profile predicting local regional recurrence of rectal cancer. Clin Cancer Res 16(10): 2811-2818.

de Maat MF, van de Velde CJ, van der Werff MP, Putter H, Umetani N, Klein-Kranenbarg EM, Turner RR, van Krieken JH, Bilchik A, Tollenaar RA, Hoon DS (2008) Quantitative analysis of methylation of genomic loci in early-stage rectal cancer predicts distant recurrence. J Clin Oncol 26(14): 2327-2335.

Derbel O, Wang Q, Desseigne F, Rivoire M, Meeus P, Peyrat P, Stella M, Martel-Lafay I, Lemaistre AI, de La FC (2013) Impact of KRAS, BRAF and PI3KCA mutations in rectal carcinomas treated with neoadjuvant radiochemotherapy and surgery. BMC Cancer 13: 200.

Edge SB (2010) AJCC Cancer Staging Manual, 7th edn. Springer: New York, NY, USA.

Esteller M (2007) Cancer epigenomics: DNA methylomes and histonemodification maps. Nat Rev Genet 8(4): 286-298.

Gaedcke J, Grade M, Jung K, Schirmer M, Jo P, Obermeyer C, Wolff HA, Herrmann MK, Beissbarth T, Becker H, Ried T, Ghadimi M (2010) KRAS and BRAF mutations in patients with rectal cancer treated with preoperative chemoradiotherapy. Radiother Oncol 94(1): 76-81.

Goel A, Xicola RM, Nguyen TP, Doyle BJ, Sohn VR, Bandipalliam P, Rozek LS, Reyes J, Cordero C, Balaguer F, Castells A, Jover R, Andreu M, Syngal S, Boland CR, Llor X (2010) Aberrant DNA methylation in hereditary nonpolyposis colorectal cancer without mismatch repair deficiency. Gastroenterology 138(5): 1854-1862.

Hur K, Cejas P, Feliu J, Moreno-Rubio J, Burgos E, Boland CR, Goel A (2013) Hypomethylation of long interspersed nuclear element-1 (LINE-1) leads to activation of proto-oncogenes in human colorectal cancer metastasis. Gut; e-pub ahead of print 23 May 2013.

Irahara N, Nosho K, Baba Y, Shima K, Lindeman NI, Hazra A, Schernhammer ES, Hunter DJ, Fuchs CS, Ogino S (2010) Precision of pyrosequencing assay to measure LINE-1 methylation in colon cancer, normal colonic mucosa, and peripheral blood cells. J Mol Diagn 12(2): 177-183.

Irizarry RA, Ladd-Acosta C, Wen B, Wu Z, Montano C, Onyango P, Cui H, Gabo K, Rongione M, Webster M, Ji H, Potash JB, Sabunciyan S, Feinberg AP (2009) The human colon cancer methylome shows similar hypo- and hypermethylation at conserved tissue-specific CpG island shores. Nat Genet 41(2): 178-186.

Kazazian Jr HH, Wong C, Youssoufian H, Scott AF, Phillips DG, Antonarakis SE (1988) Haemophilia A resulting from de novo insertion of L1 sequences represents a novel mechanism for mutation in man. Nature 332(6160): 164-166.

Klein Kranenbarg E, van de Velde CJ (2002) Surgical trials in oncology. the importance of quality control in the TME trial. Eur J Cancer 38(7): 937-942.

Lander ES, Linton LM, Birren B, Nusbaum C, Zody MC, Baldwin J, Devon K, Dewar K, Doyle M, FitzHugh W, Funke R, Gage D, Harris K, Heaford A, Howland J, Kann L, Lehoczky J, Levine R, McEwan P, McKernan K, Meldrim J, Mesirov JP, Miranda C, Morris W, Naylor J, Raymond C, Rosetti M, Santos R, Sheridan A, Sougnez C, Stange-Thomann N, Stojanovic N, Subramanian A, Wyman D, Rogers J, Sulston J, Ainscough R, Beck S, Bentley D, Burton J, Clee C, Carter N, Coulson A, Deadman R, Deloukas P, Dunham A, Dunham I, Durbin R, French L, Grafham D, Gregory S, Hubbard T, Humphray S, Hunt A, Jones M, Lloyd C, McMurray A, Matthews L, Mercer S, Milne S, Mullikin JC, Mungall A, Plumb R, Ross M, Shownkeen R, Sims S, Waterston RH, Wilson RK, Hillier LW, McPherson JD, Marra MA, Mardis ER, Fulton LA, Chinwalla AT, Pepin KH, Gish WR, Chissoe SL, Wendl MC, Delehaunty KD, Miner TL, Delehaunty A, Kramer JB, Cook LL, Fulton RS, Johnson DL, Minx PJ, Clifton SW, Hawkins T, Branscomb E, Predki P, Richardson P, Wenning S, Slezak T, Doggett N, Cheng JF, Olsen A, Lucas S, Elkin C, Uberbacher E, Frazier M, Gibbs RA, Muzny DM, Scherer SE, Bouck JB, Sodergren EJ, Worley KC, Rives CM, Gorrell JH, Metzker ML, Naylor SL, Kucherlapati RS, Nelson DL, Weinstock GM, Sakaki Y, Fujiyama A, Hattori M, Yada T, Toyoda A, Itoh T, Kawagoe C, Watanabe H, Totoki Y, Taylor T, Weissenbach J, Heilig R, Saurin W, Artiguenave F, Brottier P, Bruls T, Pelletier E, Robert C, Wincker P, Smith DR, Doucette-Stamm L, Rubenfield M, Weinstock K, Lee HM, Dubois J, Rosenthal A, Platzer M, Nyakatura G, Taudien S, Rump A, Yang H, Yu J, Wang J, Huang G, Gu J, Hood L, Rowen L, Madan A, Qin S, Davis RW, Federspiel NA, Abola AP, Proctor MJ, Myers RM, Schmutz J, Dickson M, Grimwood J, Cox DR, Olson MV, Kaul R, Raymond C, Shimizu N, Kawasaki K, Minoshima S, Evans GA, Athanasiou M, Schultz R, Roe BA, Chen F, Pan H, Ramser J, Lehrach H, Reinhardt R, McCombie WR, 
de la Bastide M, Dedhia N, Blocker H, Hornischer K, Nordsiek G, Agarwala R, Aravind L, Bailey JA, Bateman A, Batzoglou S, Birney E, Bork P, Brown DG, Burge CB, Cerutti L, Chen HC, Church D, Clamp M, Copley RR, Doerks T, Eddy SR, Eichler EE, Furey TS, Galagan J, Gilbert JG, Harmon C, Hayashizaki Y, Haussler D, Hermjakob H, Hokamp K, Jang W, Johnson LS, Jones TA, Kasif S, Kaspryzk A, Kennedy S, Kent WJ, Kitts P, Koonin EV, Korf I, Kulp D, Lancet D, Lowe TM, McLysaght A, Mikkelsen T, Moran JV, Mulder N, Pollara VJ, Ponting CP, Schuler G, Schultz J, Slater G, Smit AF, Stupka E, Szustakowski J, Thierry-Mieg D, Thierry-Mieg J, Wagner L, Wallis J, Wheeler R, Williams A, Wolf YI, Wolfe KH, Yang SP, Yeh RF, Collins F, Guyer MS, Peterson J, Felsenfeld A, Wetterstrand KA, Patrinos A, Morgan MJ, de JP, Catanese JJ, Osoegawa K, Shizuya H, Choi S, Chen YJ (2001) Initial sequencing and analysis of the human genome. Nature 409(6822): 860-921.

Lao VV, Grady WM (2011) Epigenetics and colorectal cancer. Nat Rev Gastroenterol Hepatol 8(12): 686-700.

Matlik K, Redik K, Speek M (2006) L1 antisense promoter drives tissuespecific transcription of human genes. J Biomed Biotechnol 2006(1): 71753.

McShane LM, Altman DG, Sauerbrei W, Taube SE, Gion M, Clark GM (2005) REporting recommendations for tumour MARKer prognostic studies (REMARK). Br J Cancer 93(4): 387-391.

Miki Y, Nishisho I, Horii A, Miyoshi Y, Utsunomiya J, Kinzler KW, Vogelstein B, Nakamura Y (1992) Disruption of the APC gene by a retrotransposal insertion of L1 sequence in a colon cancer. Cancer Res 52(3): 643-645.

Murata A, Baba Y, Watanabe M, Shigaki H, Miyake K, Ishimoto T, Iwatsuki M, Iwagami S, Sakamoto Y, Miyamoto Y, Yoshida N, Nosho K, Baba H (2013) Methylation levels of LINE-1 in primary lesion and matched metastatic lesions of colorectal cancer. Br J Cancer 109(2): 408-415.

Nagtegaal ID, Marijnen CA, Kranenbarg EK, Mulder-Stapel A, Hermans J, van de Velde CJ, van Krieken JH (2001) Local and distant recurrences in rectal cancer patients are predicted by the nonspecific immune response specific immune response has only a systemic effect-a histopathological and immunohistochemical study. BMC Cancer 1: 7.

Nelson HH, Marsit CJ, Kelsey KT (2011) Global methylation in exposure biology and translational medical science. Environ Health Perspect 119(11): 1528-1533.

Ogino S, Nishihara R, Lochhead P, Imamura Y, Kuchiba A, Morikawa T, Yamauchi M, Liao X, Qian ZR, Sun R, Sato K, Kirkner GJ, Wang M, Spiegelman D, Meyerhardt JA, Schernhammer ES, Chan AT, Giovannucci E, Fuchs CS (2013) Prospective study of family history and colorectal cancer risk by tumor LINE-1 methylation level. J Natl Cancer Inst 105(2): $130-140$.

Ogino S, Nosho K, Kirkner GJ, Kawasaki T, Chan AT, Schernhammer ES, Giovannucci EL, Fuchs CS (2008) A cohort study of tumoral LINE-1 hypomethylation and prognosis in colon cancer. J Natl Cancer Inst 100(23): 1734-1738.

Penzkofer T, Dandekar T, Zemojtel T (2005) L1Base: from functional annotation to prediction of active LINE-1 elements. Nucleic Acids Res 33(Database issue): D498-D500.

Perrin D, Ballestar E, Fraga MF, Frappart L, Esteller M, Guerin JF, Dante R (2007) Specific hypermethylation of LINE-1 elements during abnormal overgrowth and differentiation of human placenta. Oncogene 26(17): 2518-2524.

Rodenhiser D, Mann M (2006) Epigenetics and human disease: translating basic biology into clinical applications. CMAJ 174(3): 341-348.
Sassaman DM, Dombroski BA, Moran JV, Kimberland ML, Naas TP, DeBerardinis RJ, Gabriel A, Swergold GD, Kazazian Jr. HH (1997) Many human L1 elements are capable of retrotransposition. Nat Genet 16(1): $37-43$.

Sellis D, Provata A, Almirantis Y (2007) Alu and LINE1 distributions in the human chromosomes: evidence of global genomic organization expressed in the form of power laws. Mol Biol Evol 24(11): 2385-2399.

Slattery ML, Curtin K, Wolff RK, Boucher KM, Sweeney C, Edwards S, Caan BJ, Samowitz W (2009) A comparison of colon and rectal somatic DNA alterations. Dis Colon Rectum 52(7): 1304-1311.

Sunami E, de MM, Vu A, Turner RR, Hoon DS (2011a) LINE-1 hypomethylation during primary colon cancer progression. PLoS One 6(4): e18884.

Sunami E, de MM, Vu A, Turner RR, Hoon DS (2011b) LINE-1 hypomethylation during primary colon cancer progression. PLoS One 6(4): e18884.

Sunami E, Vu AT, Nguyen SL, Giuliano AE, Hoon DS (2008) Quantification of LINE1 in circulating DNA as a molecular biomarker of breast cancer. Ann N Y Acad Sci 1137: 171-174.

Tanemura A, Terando AM, Sim MS, van Hoesel AQ, de Maat MF, Morton DL, Hoon DS (2009) CpG island methylator phenotype predicts progression of malignant melanoma. Clin Cancer Res 15(5): 1801-1807.

Umetani N, Giuliano AE, Hiramatsu SH, Amersi F, Nakagawa T, Martino S, Hoon DS (2006a) Prediction of breast tumor progression by integrity of free circulating DNA in serum. J Clin Oncol 24(26): 4270-4276.

Umetani N, Kim J, Hiramatsu S, Reber HA, Hines OJ, Bilchik AJ, Hoon DS (2006b) Increased integrity of free circulating DNA in sera of patients with colorectal or periampullary cancer: direct quantitative PCR for ALU repeats. Clin Chem 52(6): 1062-1069.

van Engeland M, Derks S, Smits KM, Meijer GA, Herman JG (2011) Colorectal cancer epigenetics: complex simplicity. J Clin Oncol 29(10): 1382-1391.

van Nes JG, de Kruijf EM, Faratian D, van de Velde CJ, Putter H, Falconer C, Smit VT, Kay C, van de Vijver MJ, Kuppen PJ, Bartlett JM (2011) COX2 expression in prognosis and in prediction to endocrine therapy in early breast cancer patients. Breast Cancer Res Treat 125(3): 671-685.

Wang X, Fan J, Liu D, Fu S, Ingvarsson S, Chen H (2011) Spreading of Alu methylation to the promoter of the MLH1 gene in gastrointestinal cancer. PLoS One 6(10): e25913.

Weisenberger DJ, Campan M, Long TI, Kim M, Woods C, Fiala E, Ehrlich M, Laird PW (2005) Analysis of repetitive element DNA methylation by MethyLight. Nucleic Acids Res 33(21): 6823-6836.

Yoder JA, Walsh CP, Bestor TH (1997) Cytosine methylation and the ecology of intragenomic parasites. Trends Genet 13(8): 335-340.

Zeestraten EC, Kuppen PJ, van de Velde CJ, Marijnen CA (2012) Prediction in rectal cancer. Semin Radiat Oncol 22(2): 175-183.

Zhang Y, Shu J, Si J, Shen L, Estecio MR, Issa JP (2012) Repetitive elements and enforced transcriptional repression co-operate to enhance DNA methylation spreading into a promoter CpG-island. Nucleic Acids Res 40(15): 7257-7268.

This work is published under the standard license to publish agreement. After 12 months the work will become freely available and the license terms will switch to a Creative Commons AttributionNonCommercial-Share Alike 3.0 Unported License. 